\title{
O Instagram como canal de interação entre as bibliotecas e os usuários da Universidade Federal de Alagoas
}

\section{Márcio Thiago dos Santos Albuquerque}

Mestrando em Gestão da Informação e

do Conhecimento pela Universidade

Federal de Sergipe. Bibliotecário da

Universidade Federal de Alagoas.

marc.thi@hotmail.com

\section{Pablo Boaventura Sales Paixão}

Doutor em Ciência da Informação pela

Universidade Complutense de Madri.

Professor permanente do PPGCI/UFS

pabloboaventura1@hotmail.com

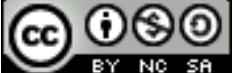

Este trabalho está licenciado com uma Licença Creative Commons - AtribuiçãoNãoComercial-Compartilhalgual 3.0 Brasil.

\section{Resumo}

Diante dos avanços tecnológicos, principalmente na esfera informacional, é necessário que as instituições que lidam com informação estejam em sintonia com seus usuários nos diversos ambientes. Nesse contexto, a utilização das redes sociais pelas bibliotecas é imprescindível para se relacionar com seus públicos, estes cada vez mais imersos na cultura digital. Assim, este texto visa analisar a utilização da rede social Instagram pelas bibliotecas que compõem o Sistema de Bibliotecas da Universidade Federal de Alagoas (SiBi-UFAL). O objetivo desse estudo é investigar como as bibliotecas que compõem o $\mathrm{SiBi} / \mathrm{UFAL}$ utilizam a rede social Instagram, baseando-se em algumas variáveis referentes ao Marketing digital como: presença online, audiência e engajamento. A pesquisa é do tipo exploratória, de caráter descritivo, utilizando-se da abordagem quantitativa. O universo da pesquisa é composto por 14 bibliotecas que compõem o SiBi-UFAL, tendo como amostra 06 bibliotecas que possuem perfis da rede social em tela. As análises demonstraram que apenas a realização de postagens frequentes não promove necessariamente 0 fortalecimento dos laços com seus usuários, por parte dessas Bibliotecas.

Palavras-chave: Marketing digital. Redes sociais. Bibliotecas Universitárias.

Instagram as an interaction channel between libraries and users of the Federal University of Alagoas

\section{Abstract}

In front of technological advances, especially in the informational sphere, it is necessary that institutions that deal with information are in tune with their users in different environments. In this context, the use of social networks by libraries is essential to relate with their public, who are increasingly immersed in digital culture. Thus, this text aims to analyze the use of the social network Instagram by the libraries that make up the Library System of the Federal University of Alagoas (SiBi-UFAL). The objective of this study is to investigate how the libraries that compose SiBi/UFAL use the social network Instagram, based on some variables related to digital marketing such as: online presence, audience and engagement. The research is exploratory, descriptive, using the quantitative approach. The research universe consists of 14 libraries that compose the $\mathrm{SiBi}$ UFAL, with a sample of 06 libraries that have profiles of the social network on screen. The analyzes showed that just making frequent posts does not necessarily promote the strengthening of ties with its users, by these Libraries.

Keywords: Digital marketing. Social networks. University libraries. 


\section{Introdução}

Os avanços tecnológicos têm acarretado profundas transformações na sociedade numa velocidade que apresenta características exponenciais (LONGO, 2014). No âmbito informacional, uma maior propagação das Tecnologias Digitais de Informação e Comunicação (TDIC), tendo a internet como sua principal representante, tem implicado na produção e disseminação de informações que transcendem à capacidade de processamento cognitivo dos cidadãos, principalmente quando comparada com a capacidade de produção informacional do suporte físico, analógico.

De acordo com as pesquisas de We Are Social e Hootsuite (KEMP, 2018), existem mais de 4 bilhões de pessoas em todo o mundo que utilizam a internet. Este número representa aproximadamente $52,63 \%$ da população mundial, estimando a existência de 7,6 bilhões de seres humanos. No Brasil, esse mesmo relatório apresenta que 150 milhões de brasileiros são usuários da internet, em torno de $70 \%$ da população.

É necessário que as unidades de informação, especialmente as bibliotecas, acompanhem tais avanços, a fim de fazerem uso das Tecnologias Digitais da Informação e Comunicação, especialmente das redes sociais, para a promoção do empoderamento informacional. (GARCIA; SÁ, 2017). Para tanto, devem estar atentas aos novos parâmetros relacionados à comunicação, socialização e ao acesso à informação (GULKA; LUCAS; CORREA, 2018).

No âmbito profissional especialmente, os bibliotecários necessitam compreender o perfil informacional e tecnológico dos seus usuários, assim como o contexto social no qual sua unidade se faz presente. Isso em razão dos diferentes tipos de bibliotecas existentes. Dentre estas estão as bibliotecas universitárias, que aparecem na Idade Média acompanhadas das primeiras universidades, dando início a um novo momento onde os livros ultrapassam a barreira da religiosidade, ocupando outros territórios temáticos (MILANESI, 2013).

A biblioteca universitária na contemporaneidade, ao marcar presença no mundo digital, abre possibilidades relacionadas à ampliação da sua inserção social, atingindo um público que vai além de suas instalações físicas. A presença digital é formada pelos produtos e serviços de informação da biblioteca, pautados na web e que atendem as necessidades informacionais da comunidade, a fim de criar e disseminar conteúdo relevante e engajador por meio das mídias sociais. (PRADO; CORREA, 2016).

Vê-se um cenário onde os cidadãos estão abertos às potencialidades dialógicas da informação digital, pois "os conteúdos eletrônicos e digitais, as novas mídias e formatos exigem que as bibliotecas desenvolvam em suas equipes competências e habilidades para o manuseio efetivo desses recursos tecnológicos" (VALENTIM, 2016, p. 30). Por meio das redes sociais, o usuário passa a ter voz e, como consequência, torna-se mais crítico no tocante aos serviços disponibilizados pela biblioteca.

De acordo com Kemp (2018), o relatório da We Are Social e Hootsuite, de 2018, demonstra que o Brasil tem mais de 140 milhões de usuários ativos nas redes sociais e que a rede social Instagram aparece em quarto lugar no ranking das redes sociais mais utilizadas no país, atrás apenas do Youtube, Facebook e WhatsApp (RIBEIRO, 2019).

É importante destacar que a escolha da rede social Instagram para o presente estudo se deu pelo fato de ser a que apresenta maior popularidade e adesão entre as unidades que compõem o SiBi-UFAL, possuindo maior frequência quanto às postagens entre as referidas bibliotecas. Além disso, a rede em questão proporciona a colaboração na construção da imagem da biblioteca e incentiva o usuário a voltar o olhar para as atividades por ela desenvolvidas, assim como percebê-la como local vivo e dinâmico capaz de oferecer diferentes experiências no que se refere à construção de conhecimento (GARCIA; SÁ, 2017).

Com base no exposto questiona-se: as bibliotecas que compõem o Sistema de Bibliotecas da Universidade Federal de Alagoas (SiBi-UFAL) têm utilizado a rede social Instagram como ferramenta de interação com seus usuários, fazendo uso do marketing digital para ampliar sua presença aos novos espaços cada vez mais dinâmicos que a sociedade se encontra atualmente? 
É objetivo do presente estudo, investigar como as bibliotecas que compõem o SiBi/UFAL utilizam a rede social Instagram, baseando-se em algumas variáveis referentes ao Marketing digital como: presença online, audiência e engajamento.

\section{Marketing Digital em Unidades de Informação}

As constantes transformações nas maneiras pelas quais as unidades de informação gerenciam as crescentes produções informacionais no suporte digital alteram o comportamento informacional da sociedade, especialmente dos jovens estudantes. Também, devido às mídias sociais, há mudanças na forma de interagir entre as pessoas, possibilitando, por exemplo, novas formas de interação entre tais unidades e seus usuários, para além das barreiras geográficas e demográficas. Por meio das mídias sociais, os cidadãos têm a sensação de pertencimento às comunidades, e isso é uma forma de inclusão social (KOTLER; KARTAJAYA; SETIAWAN, 2017).

Com todas essas mudanças, a Biblioteconomia e a Ciência da Informação, dentre outras áreas que trabalham com a informação, têm sofrido alterações com o intuito de acompanhar esse novo cenário de dialogicidade e interações. Nesse cenário, o Marketing tem se configurado como uma boa ferramenta de comunicação para diversas organizações, a exemplo das bibliotecas e seus clientes (usuários), pois trata-se de "[...] uma atividade, conjunto de instituições e processos para criar, comunicar, entregar e trocar ofertas que têm valor para clientes, parceiros e sociedade em geral" (AMERICAN MARKETING ASSOCIATION, 2017, [não paginado], tradução nossa).

No tocante ao marketing nas unidades de informação, principalmente no que se refere às mídias sociais utilizadas por tais espaços, vê-se que há uma relação profícua para a disseminação da informação dos produtos e serviços oferecidos por essas unidades. Neves (2018) traz o seguinte conceito sobre Marketing Digital para unidades de informação:

O marketing digital para unidades de informação é compreendido como uma importante estratégia para que instituições como as bibliotecas possam potencializar a atração de usuários integrantes, a divulgação de forma exponencial, de seus produtos e serviços de informação e como recurso capaz de proporcionar ao bibliotecário as estratégias necessárias para desenvolver a presença digital nas mídias sociais. (NEVES, 2018, p. 219).

É importante lembrar que as bibliotecas, sejam elas escolares, universitárias e especializadas, são instituições sem fins lucrativos e que, por essa razão, o marketing deve estar voltado à satisfação das necessidades e carências relacionadas à informação, por parte dos usuários (GULKA; LUCAS; CORREA, 2018).

O uso das mídias sociais tem sua importância no que se refere à promoção dos produtos e serviços que a biblioteca oferece, apresentando-se como uma forma mais rápida de promover a circulação da informação (ARAUJO; ARAÚJO, 2018). Do mesmo modo, é dado ao usuário mais autonomia para disseminar informações, ganhando mais poder no processo de comunicação e implicando na produção de conhecimento em tempo real (SOUSA FILHO; VIEIRA, 2017).

Nesse contexto, a biblioteca precisa de visibilidade, mostrar-se e interagir com a sua comunidade. Araujo e Araújo (2018) defendem que a biblioteca deve ser vista como negócio e adotar as estratégias de marketing, com o intuito de manter e atrair novos usuários. Para isso, deve-se, por exemplo, impulsionar a visibilidade de seus serviços. Para os autores, a promoção da biblioteca em relação ao uso das mídias sociais pode ser avaliada por indicadores de valores que mensuram $e$ auxiliam no processo de conteúdo divulgado.

Os indicadores de valores, acima mencionados, são conhecidos como métricas, que, segundo Macedo (2014), são sistemas de mensuração fundamentais na identificação das proporções apropriadas para o uso e investimento em cada canal.

Sendo assim, a utilização de métricas torna-se algo fundamental, uma vez que indicam como o marketing está impactando no planejamento das unidades de informação, tornando-se um auxílio para os gestores na tomada de decisão, trazendo benefícios em relação ao retorno por parte dos usuários com o intuito de melhorar o conteúdo a ser publicado (ARAUJO; ARAÚJO, 2018). 


\section{Procedimentos Metodológicos}

A pesquisa apresenta-se como exploratória uma vez que "[...] busca apenas levantar informações sobre um determinado objeto, delimitando assim um campo de trabalho, mapeando as condições desse objeto" (SEVERINO, 2007, p. 123), além de ter característica descritiva. Por se tratar da análise de métricas da rede social Instagram, viu-se necessária a utilização da abordagem quantitativa, pois entre as suas características estão a unicidade da maneira de coletar e tratar os dados, de se basear em procedimentos estatísticos, além de auxiliar na identificação de regularidades como perfil e tendências (LIMA, 2016). O universo da pesquisa é composto pelas 14 bibliotecas $^{1}$ que compõem o SiBi-UFAL, sendo a amostra 06 bibliotecas que possuem perfis da rede social Instagram.

As postagens analisadas neste estudo foram publicadas durante o mês de março de 2019, sendo marco temporal de um mês considerado expressivo para investigar principalmente questões relacionadas a periodicidade das publicações e da interação com seus seguidores.

Posteriormente, em dezembro de 2019, foram recuperadas informações referentes ao número de seguidores e quantidade de publicações, com intuito de se fazer um comparativo com o mês de abril, data em que foi realizada a investigação inicial.

Para alcançar o objetivo proposto, optou-se por fazer captura de tela de todas as postagens, em seguida foi definida a observação dos seguintes aspectos: audiência, onde foi observado o número de seguidores e frequência de publicação; e o engajamento, atendo-se a quantidade de curtidas, comentários e visualizações (MACEDO, 2014).

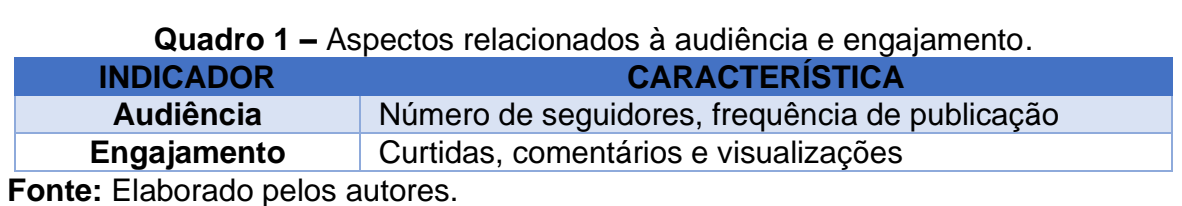

De acordo com Macedo (2014), há inúmeras métricas que podem ser utilizadas nas plataformas digitais, mas não é recomendável fazer uso de um número alto delas. Logo, para o estudo em questão, optou-se por utilizar algumas relativas à audiência e ao engajamento. As métricas relacionadas à audiência objetivam o entendimento no que se refere ao conteúdo que está sendo exibido nas mídias, assim como o tamanho da audiência que está sendo alcançada por tais informações. Já as relacionadas ao engajamento, atentam para avaliação de como e quanto o público está interagindo com a marca e seus conteúdos (MACEDO, 2014).

\section{Resultados e Discussão}

No primeiro levantamento, que teve como informações analisadas os dados referentes ao mês de março de 2019, observouse inicialmente aspectos relacionados ao engajamento (curtidas, comentários, visualizações). Entende-se que a ação de curtir seja vista como um "termômetro" do que os usuários estão achando sobre as postagens, pois segundo Araujo e Araújo (2018, p. 187), tal ação "[...] pode ser considerada uma forma de apoio e concordância, funcionando como uma espécie de legitimação do conteúdo [...]".

O quadro 2 demonstra que a interação dos seguidores com os perfis das bibliotecas é significativa, com exceção da B3 que apresentou apenas 7 curtidas durante o período analisado. Este baixo número se explica pelo fato da referida unidade de informação ter feito sua primeira postagem no final do mês analisado, como pode ser observado mais adiante no quadro 3.

\footnotetext{
${ }^{1}$ Para uma melhor representação, foi atribuída uma sigla para cada biblioteca, as quais são apresentadas nos quadros 2,3 e 4.
} 
Quadro 2 - Interação com os seguidores do Instagram durante o mês de março de 2019.

\begin{tabular}{|c|c|c|c|c|c|c|}
\hline SIGLA & BIBLIOTECA & POSTAGENS & $\begin{array}{l}\text { CURTIDAS/ } \\
\text { VISUALIZAÇÕES }\end{array}$ & COMENTÁRIO & STORIES & $\begin{array}{l}\text { VISUALIZAÇÕES } \\
\text { DOS STORIES }\end{array}$ \\
\hline B1 & Biblioteca Central & 21 & 1243 & 20 & 7 & 550 \\
\hline B2 & $\begin{array}{l}\text { Biblioteca Campus } \\
\text { Arapiraca }\end{array}$ & 24 & 1187 & 37 & 35 & 4235 \\
\hline B3 & $\begin{array}{l}\text { Biblioteca Polo } \\
\text { Penedo }\end{array}$ & 1 & 7 & — & - & - \\
\hline B4 & $\begin{array}{l}\text { Biblioteca Campus } \\
\text { Delmiro Gouveia }\end{array}$ & 16 & 792 & 19 & 80 & 6631 \\
\hline B5 & $\begin{array}{l}\text { Biblioteca Polo } \\
\text { Santana }\end{array}$ & 4 & 149 & 11 & 8 & 418 \\
\hline
\end{tabular}

Fonte: Elaborado pelos autores.

A B1, com 1243 curtidas, possui a média mais alta na amostra (cerca de 59 curtidas por postagem) e apesar de ser um dos perfis mais recentes entre os pesquisados, nota-se que o engajamento é bastante expressivo. É válido lembrar que se trata da Biblioteca Central, localizada no Campus A. C. Simões, em Maceió, a qual presta atendimento ao maior número de usuários da instituição. Outra característica importante é que esta unidade possui uma equipe de comunicação, que planeja e filtra as informações de cunho acadêmico em sua maioria, composta por alguns servidores voltados para esse tipo de trabalho. Observou-se ainda, que nas imagens postadas pela B1 há a logomarca do SiBi-UFAL. Esse cuidado em relação à imagem institucional pode demonstrar que há interesse em aprimorar e unificar o uso das redes sociais.

O mesmo não ocorre com as demais bibliotecas, que possuem número reduzido de servidores, onde muitas vezes esse tipo de trabalho acaba ficando em segundo plano devido à grande demanda de serviços, tais como processamento técnico, educação de usuários etc.

Em seguida aparecem as B2 e B4, ambas com aproximadamente 49 curtidas por postagem. Vale ressaltar que tais bibliotecas também são, depois da Biblioteca Central, as que possuem maior número de usuários por estarem nas cidades sedes de campi muito importante para as regiões do Agreste e Sertão de Alagoas, Arapiraca e Delmiro Gouveia, respectivamente. Portanto, tais campi concentram o maior número de cursos da UFAL, fora da capital.

Para Araujo e Araújo (2018) a presença nas redes sociais pode trazer certa visibilidade. Contudo, o engajamento, ou seja, aspectos relacionados à interação dos seguidores por meio de curtidas, comentários e visualizações, somente é gerado por meio da produção de conteúdos que despertem o interesse dos usuários. Para tanto, é imprescindível criar mecanismos de escuta para compreender as temáticas de maior interesse, ações de interação que mais chamam a atenção etc.

Sobre a quantidade de comentários, é notório que este tipo de ação apresenta números mais baixos comparados aos da ação de curtir (na média geral cerca de 2,6\%). Isso se deve, de acordo com Araujo e Araújo (2018) ao fato de que a ação de comentar exige um comprometimento maior dos usuários para com o conteúdo produzido nas mídias sociais.

No que diz respeito à frequência das postagens no período analisado (março de 2019), nota-se que a B2 foi a que mais fez publicações (24 postagens), seguida da B1 (21 postagens), da B4 (16 postagens), B5 (4 postagens) e B3 com apenas uma postagem. Esse tópico deve ser bem explorado, uma vez que manter uma frequência de publicações é importante para que os usuários se engajem mais, aumentando assim a visibilidade da instituição (ARAUJO; ARAÚJO, 2018).

Já sobre a quantidade de publicações de Stories $^{2}$, as bibliotecas B4 e B2 se destacam, pois foram realizadas 80 (B4) e 35 (B2) interações. A soma de suas visualizações totaliza 6.631 e 4.253, respectivamente. Percebe-se, ainda, que em todas as bibliotecas, excetuando-se o perfil da B3, a abrangência que esse recurso obteve foi maior que o número de curtidas, pois a B2 apresentou uma média de aproximadamente 121 visualizações por stories, seguida da B4 com média de 83 . Vale ressaltar que a biblioteca referente à $\mathrm{B} 3$, trata-se de um polo educacional e não de um Campus, por conta disso, deve-se levar em consideração aspectos como quantidade de funcionários reduzida, por exemplo, pois existe apenas uma

\footnotetext{
${ }^{2}$ Postagem que fica visível por até $24 \mathrm{~h}$.
} 
bibliotecária na unidade em questão, e isso pode interferir nos resultados comparados às outras unidades, uma vez que as demais bibliotecas presentes no quadro 2 possuem ao menos dois bibliotecários.

Acredita-se que devido a instantaneidade e abrangência, aspectos característicos da rede social analisada, a maioria das unidades de informação em questão optaram por utilizar Stories, em comparação às postagens convencionais (no perfil da página), pois tornou-se uma boa ferramenta de disseminação de avisos, divulgações de eventos, entre outros.

$\mathrm{Na}$ intenção de se fazer um comparativo quanto ao crescimento do número de seguidores e a quantidade de postagens, recuperou-se, em dezembro de 2019, informações referentes a esses segmentos. Esses dados mostrariam, por exemplo, caso alguma biblioteca deixasse de possuir o perfil da rede estudada, ou se alguma outra iniciou tal utilização. Além de demonstrar se houve aumento no que se refere à audiência e engajamento.

O quadro 3 apresenta dados comparativos no que diz respeito à quantidade de seguidores e de publicações apenas das 6 bibliotecas que possuíam perfil no Instagram no primeiro período analisado (abril de 2019), pois, por se tratar de um estudo comparativo, não foram incluídas no referido quadro outras duas bibliotecas que começaram posteriormente a utilizar tal rede social. Esses novos perfis, juntamente com as demais bibliotecas que completam o SiBi/UFAL, encontram-se mais adiante no quadro 4.

Quadro 3 - Dados sobre o Instagram das Bibliotecas do SIBI-UFAL.

\begin{tabular}{|c|c|c|c|c|c|c|}
\hline SIGLA & BIBLIOTECA & $\begin{array}{c}\text { № DE } \\
\text { SEGUIDORES } \\
18 / 04 / 2019\end{array}$ & $\begin{array}{c}\text { № DE } \\
\text { SEGUIDORES } \\
19 / 12 / 2019\end{array}$ & $\begin{array}{c}\text { № DE } \\
\text { PUBLICAÇÕES } \\
\text { 18/04/2019 }\end{array}$ & $\begin{array}{c}\text { № DE } \\
\text { PUBLICAÇÕES } \\
\text { 19/12/2019 }\end{array}$ & $\begin{array}{l}\text { DATA DA } 1 \underline{a} \\
\text { POSTAGEM }\end{array}$ \\
\hline B1 & $\begin{array}{l}\text { Biblioteca } \\
\text { Central }\end{array}$ & 590 & 2.428 & 68 & 697 & $27 / 02 / 19$ \\
\hline B2 & $\begin{array}{l}\text { Biblioteca } \\
\text { Campus } \\
\text { Arapiraca }\end{array}$ & 1.001 & 1.179 & 347 & 704 & 04/08/17 \\
\hline B3 & $\begin{array}{l}\text { Biblioteca Polo } \\
\text { Penedo }\end{array}$ & 102 & 169 & 1 & 20 & $30 / 03 / 19$ \\
\hline B4 & $\begin{array}{l}\text { Biblioteca } \\
\text { Campus Delmiro } \\
\text { Gouveia }\end{array}$ & 527 & 867 & 59 & 162 & 29/08/18 \\
\hline B5 & $\begin{array}{l}\text { Biblioteca Polo } \\
\text { Santana }\end{array}$ & 291 & 536 & 20 & 38 & $05 / 04 / 18$ \\
\hline B6 & $\begin{array}{l}\text { Biblioteca } \\
\text { Setorial CECA }\end{array}$ & 135 & 327 & 0 & 23 & $27 / 06 / 19$ \\
\hline TOTAL & 2.646 & 5.506 & 495 & 1.644 & & \\
\hline
\end{tabular}

Fonte: Elaborado pelos autores.

Com relação aos indicadores de audiência na rede, principalmente no que diz respeito ao número de seguidores, nota-se que houve um significativo aumento em todas as unidades de informação do quadro, destacando-se a B1 (com aumento de mais de $300 \%$ ), B6 (aumento de mais de 140\%) e a B5 (aumento de mais de $84 \%$ ). Em números absolutos, houve um acréscimo total de mais de 2800 novos seguidores (aumento de cerca de 108\%).

É importante destacar que mais da metade de todo esse aumento se deu no perfil da B1, correspondente à Biblioteca Central. Como informado anteriormente, trata-se da unidade de informação que presta assistência ao maior número de usuários da instituição, e que possui equipe específica para o gerenciamento das redes sociais da unidade de informação.

De maneira semelhante, observou-se o crescimento quanto à quantidade de publicações, pois, ao todo, esse crescimento foi de cerca de $232 \%$. Isso demonstra que as unidades de informação estão fazendo uso dessa ferramenta com o propósito de se aproximar cada vez mais do seu público.

O quadro 4 apresenta as demais bibliotecas do SiBi/UFAL e, como dito anteriormente, mais duas bibliotecas (B7 e B8) começaram a fazer uso da rede social Instagram após o mês de abril de 2019. Com esses novos perfis, o SiBi/UFAL passa a ter presença na rede social analisada em mais da metade de suas unidades e servindo de inspiração para outras. 
Quadro 4 - Dados do Instagram das Bibliotecas do SIBI-UFAL que não possuíam perfis (abril de 2019).

\begin{tabular}{|c|c|c|c|c|c|c|}
\hline SIGLA & BIBLIOTECAS & $\begin{array}{c}\text { № DE } \\
\text { SEGUIDORES } \\
\text { 18/04/2019 }\end{array}$ & $\begin{array}{c}\text { № DE } \\
\text { SEGUIDORES } \\
\text { 19/12/2019 }\end{array}$ & $\begin{array}{c}\text { № DE } \\
\text { PUBLICAÇÕES } \\
18 / 04 / 2019\end{array}$ & $\begin{array}{c}\text { № DE } \\
\text { PUBLICAÇÕES } \\
\text { 19/12/2019 }\end{array}$ & $\begin{array}{l}\text { DATA DA } 1^{\mathrm{a}} \\
\text { POSTAGEM }\end{array}$ \\
\hline B7 & $\begin{array}{lr}\text { Biblioteca } & \text { Polo } \\
\text { Palmeira } & \text { dos } \\
\text { Índios } & \end{array}$ & --- & 114 & --- & 10 & 03/09/19 \\
\hline B8 & Biblioteca CEDU & --- & 529 & --- & 105 & 06/05/19 \\
\hline B9 & $\begin{array}{l}\text { Biblioteca Polo } \\
\text { Viçosa }\end{array}$ & --- & --- & --- & --- & --- \\
\hline B10 & $\begin{array}{l}\text { Biblioteca } \\
\text { Setorial de } \\
\text { Física }\end{array}$ & --- & --- & --- & --- & --- \\
\hline B11 & $\begin{array}{l}\text { Biblioteca } \\
\text { Setorial de } \\
\text { Matemática }\end{array}$ & --- & --- & --- & --- & --- \\
\hline B12 & $\begin{array}{l}\text { Biblioteca } \\
\text { Setorial de } \\
\text { Química }\end{array}$ & --- & --- & --- & --- & --- \\
\hline B13 & $\begin{array}{l}\text { Biblioteca } \\
\text { Setorial PPGLL } \\
\text { (Pós graduação) }\end{array}$ & --- & --- & --- & --- & --- \\
\hline B14 & $\begin{array}{l}\text { Biblioteca } \\
\text { Setorial do } \\
\text { Espaço Cultural }\end{array}$ & --- & --- & --- & --- & --- \\
\hline
\end{tabular}

Fonte: Elaborado pelos autores.

Pode-se inferir que a não presença das demais bibliotecas no Instagram pode ser ocasionada pela falta de algum tipo de suporte, seja ele material ou humano, uma vez que em algumas unidades o número de funcionários e/ou bibliotecários são muito escassos. Outro ponto relevante é que não há normativo institucional que apresente diretrizes acerca da utilização e gerenciamento das redes sociais por parte das bibliotecas do sistema, conforme se pôde observar no portal eletrônico do $\mathrm{SiBi} / \mathrm{UFAL}{ }^{3}$.

\section{Considerações Finais}

As análises apontam que em relação à presença online, cerca de $57 \%$ das bibliotecas que compõem o SiBi-Ufal possuem perfil na rede social analisada, e essa porcentagem poderia ser maior se houvesse um documento institucional que apresentassem as diretrizes sobre a criação e gerenciamento de redes sociais. Certamente esse documento ajudaria na criação, manutenção e interação de suas páginas, auxiliando principalmente nas unidades de informação com poucos servidores.

Sobre a audiência, nota-se que a quantidade de seguidores é bem expressiva e com tendência a crescer, pois cada vez mais a população se faz presente no meio digital e a biblioteca tem o papel de estar onde seu público estiver, tornando a comunicação mais próxima. Sobre a quantidade de publicações, entende-se que esta não é por si só sinônimo de aproximação do público com a unidade de informação, é preciso estreitar os laços por meio de feedbacks rápidos e que a rede social Instagram pode ser um bom caminho para isso.

Quanto ao engajamento, ou seja, a reação dos seus usuários (número de curtidas e comentários), também verificou-se quantidades expressivas, porém, bem abaixo da quantidade de visualizações que o recurso stories. Logo, cabe às bibliotecas verificar se as informações que elas estão publicando são consideradas relevantes pelos seus seguidores. Isso pode ser realizado por meio de enquetes no próprio recurso Stories.

Percebe-se que as unidades do SiBi-UFAL apresentam potencial para a atuação das redes sociais, visto que, nas bibliotecas que tem presença digital, foi identificado empenho por parte dos administradores das contas em manter uma relativa assiduidade. Além disso, estar presente nos diferentes ambientes e, principalmente, comunicar-se na linguagem de

${ }^{3}$ sibi.ufal.br 
seus usuários é um desafio para as Bibliotecas Universitárias e as redes sociais podem ser usadas como ferramentas auxiliadoras neste desafio.

Os dados analisados no presente estudo fornecem subsídios para que as unidades de informações envolvidas no $\mathrm{SiBi} / \mathrm{UFAL}$ possam realizar seus planejamentos e verificar quais estratégias ligadas ao marketing digital precisam ser melhoradas, buscando a promoção da própria Instituição.

Sugere-se a criação de um setor ou uma coordenação geral, que elabore documentos que guiem o uso das redes sociais e que haja integração entre todos os profissionais envolvidos nessa tarefa, para que assim, a presença digital das Bibliotecas aqui analisadas seja consolidada e os laços com seus usuários sejam estreitados, afinal trata-se de um sistema.

Portanto, devido sua importância, vê-se que o tema em questão necessita de mais discussões sobre o processo que envolve as mídias sociais em bibliotecas e o marketing digital, uma vez que não foi intenção deste estudo esgotar todas as questões sobre o tema e espera-se que outros trabalhos surjam a fim de que haja uma base sólida na construção dos temas aqui abordados.

\section{Referências}

AMERICAN MARKETING ASSOCIATION. Definitions of marketing. [2017]. Disponível em: https://www.ama.org/the-definition-ofmarketing-what-is-marketing/ Acesso em: 26 mar. 2020.

ARAUJO, Ronaldo Ferreira; ARAÚJO, Janiele Oliveira de. O uso das redes sociais como estratégias de marketing em unidades de informação: estudo de caso da biblioteca pública Estadual Graciliano Ramos. Revista Brasileira de Biblioteconomia e Documentação, São Paulo, v 14, n. 2, 176-196, 2018. Disponível em: https://rbbd.febab.org.br/rbbd/article/view/73. Acesso em: 16 abr. 2019.

GARCIA, Isabele Oliveira dos Santos; SÁ, Maria Irene da Fonseca e. Bibliotecas no Instagram: um estudo sobre o uso do aplicativo por unidades de informação. Prisma.com: Revista de Ciências e Tecnologias de Informação e Comunicação, Porto, n. 35, p. 108-151, 2017. Disponível em: http://twixar.me/cwpK. Acesso em: 06 abr. 2019.

GULKA, Juliana Aparecida; LUCAS, Elaine Rosangela de Oliveira; CORREA, Elisa Cristina Delfini. O uso do marketing digital em bibliotecas. Ciência da Informação em Revista, Maceió, v. 5, n. 1, p. 59-69, jan./abr. 2018. Disponível em: http://www.seer.ufal.br/index.php/cir/article/view/4104. Acesso em: 18 dez. 2019.

KEMP, Simon. Digital in 2018: world's internet users pass the 4 billion mark. In: WE are social. New York, 30 jan. 2018. Disponível em: https://wearesocial.com/blog/2018/01/global-digital-report-2018. Acesso em: 5 jan. 2019.

KOTLER, Philip; KARTAJAYA, Hermawan; SETIAWAN, Iwan. Marketing 4.0: do tradicional ao digital. Rio de Janeiro: Sextante, 2017.

LIMA, Márcia. Introdução aos métodos quantitativos em ciências sociais. In: MÉTODOS de pesquisa em Ciências Sociais: bloco quantitativo. São paulo: Sesc São Paulo/CEBRAP, 2016. p. 10-31. E-book. Disponível em: http://bibliotecavirtual.cebrap.org.br/arquivos/2017 E-BOOK\%20Sesc-Cebrap \%20Metodos\%20e\%20tecnicas \%20em\%20CS\%20\%20Bloco\%20Quantitativo.pdf. Acesso em: 25 fev. 2019.

LONGO, Walter. Marketing e comunicação na era pós-digital: as regras mudaram. São Paulo: HSM do Brasil, 2014.

MACEDO, T. Métricas de marketing digital sua aplicação nas ações de marketing das organizações: estudo de caso múltiplos. 2014. 119f. Dissertação (Mestrado em Administração) - Programa de Pós-Graduação em Administração, Escola de Administração, Universidade Federal do Rio grande do Sul, Porto Alegre, 2014. Disponível em: https://lume.ufrgs.br/handle/10183/101499. Acesso em: 26 mar. 2020

MILANESI, Luís. Biblioteca. 3.ed. Cotia, SP: Ateliê editorial, 2013.

NEVES, Barbara Coelho. Aproximação conceitual e possibilidades do marketing digital: o bibliotecário estrategista em mídias sociais. Pesquisa Brasileira em Ciência da Informação e Biblioteconomia, João Pessoa, v. 13, n. 1, p. 214-225, 2018. Disponível em: https://periodicos.ufpb.br/index.php/pbcib/article/view/39354. Acesso em: 18 dez. 2019.

PRADO, Jorge Moisés Kroll do; CORREA, Elisa Cristina Delfini. Bibliotecas universitárias e a presença digital: estabelecimento de diretrizes para o uso de mídias digitais. Perspectivas em Ciência da Informação, Belo Horizonte, v. 21, n. 3, p. 165-181, jul./set. 2016. Disponível em: http://twixar.me/VwpK. Acesso em: 20 mar. 2019.

RIBEIRO, Carolina. Conheça as redes sociais mais usadas no Brasil e no mundo em 2018: relatório revela dados e tendências sobre o uso das redes sociais no Brasil e ao redor do mundo. In: TECHTUDO. Rio de Janeiro, 15 fev. 2019. Disponível em:

https://www.techtudo.com.br/noticias/2019/02/conheca-as-redes-sociais-mais-usadas-no-brasil-e-no-mundo-em-2018.ghtml. Acesso em: 18 dez. 2019.

SEVERINO, Antônio Joaquim. Metodologia do trabalho científico. 23. ed. rev. e atual. São Paulo: Cortez, 2007. 
SOUSA FILHO, Agenor Leandro de; VIEIRA, David Vernon. O uso de mídias sociais como estratégia de marketing. Um olhar sobre a biblioteca universitária das universidades federais da região Nordeste do Brasil. In: CONGRESSO BRASILEIRO DE BIBLIOTECONOMIA, DOCUMENTAÇÃO E CIÊNCIA DA INFORMAÇÃO, 27., 2017, Fortaleza. Anais [...]. Fortaleza: Febab, 2017. Disponível em: https://portal.febab.org.br/anais/article/view/1968. Acesso em: 19 dez. 2019.

VALENTIM, Marta Lígia Pomim. O perfil das bibliotecas contemporâneas. In: RIBEIRO, Anna Carolina Mendonça Lemos; FERREIRA, Pedro Cavalcanti Gonçalves. Biblioteca do século XXI: desafios e perspectivas. Brasília: Ipea, 2016. p.19-42. E-book. Disponível em: http://www.ipea.gov.br/portal/index.phpoption=com content\&view=article\&id=29215\&ltemid=419. Acesso em: 14 abr. 2019.

Artigo submetido em: 10/04/2020. Aceito em: 17/04/2020.

\section{URIVERSIDADE FEDERAL DO CARIRI}

Este periódico é uma publicação do Programa de Pós-Graduação em Biblioteconomia da Universidade Federal do Cariri em formato digital e periodicidade quadrimestral. 